\title{
Quantificação laboratorial de cobre sérico por espectrofotometria Vis comparável à espectrometria de absorção atômica com chama
}

\author{
Laboratorial quantification of serum copper by Vis spectrophotometry in comparison to flame \\ atomic absorption spectrometry
}

Angela Maria Moro'; Denise Grotto²; Rachel Bulcão ${ }^{3}$ Valdeci J. Pomblum4; Denise Bohrer ${ }^{5}$; Leandro M. de Carvalho ${ }^{6}$; Sandra Oliveira ${ }^{7}$; Solange Cristina Garcia ${ }^{8}$

unitermos
Cobre
Soro
EAA-chama
Espectrofotometria VIS

Espectrofotometria VIS

\section{resumo}

Introdução: O cobre é um nutriente essencial para os humanos, e a manutenção dos seus níveis é importante, uma vez que seu metabolismo está envolvido com estresse oxidativo e patologias, como a Doença de Wilson. Neste trabalho, um método de espectrofotometria visível (espectrofotometria Vis) foi validado, aplicado em indivíduos jovens e comparado com espectrometria de absorção atômica com chama (EAA-chama). Métodos: Concentrações séricas de cobre foram medidas por EAA-chama e por espectrofotometria Vis, através da reação de cobre com batocuproína, $\lambda=484 \mathrm{~nm}$. Curvas analíticas em solução aquosa e com adição de padrão foram efetuadas para verificar linearidade, recuperação e precisão do método espectrofotométrico. Amostras de sangue de 12 indivíduos (média de idade 22 anos) foram analisadas por ambos os métodos e comparadas entre si. Os resultados foram expressos em média \pm desviopadrão. Resultados: As curvas com adição de padrão e aquosa $(n=5)$ apresentaram coeficientes de regressão superiores a 0,99 e de variação inter e intradia inferiores a $15 \%$. Os valores de cobre sérico encontrados para o método espectrofotométrico foram 1,17 $\pm 0,39$ e 0,73 $\pm 0,14 \mathrm{mg} / \mathrm{l}$ para mulheres e homens, respectivamente. Para EAA-chama foram encontrados 1,13 $\pm 0,43$ e 0,59 $\pm 0,13 \mathrm{mg} / \mathrm{l}$ para mulheres e homens, respectivamente. Os resultados mostraram correlação de Pearson significativa $(r=0,946 ; p<0,05)$. Os níveis séricos de cobre foram significativamente maiores em mulheres do que em homens $(p<0,05)$. Conclusão: O método espectrofotométrico visível demonstrou ser linear, reprodutível e aplicável, oferecendo uma alternativa confiável à quantificação de cobre por EAA-chama. Além disso, é uma técnica simples, rápida e barata, que pode ser utilizada na rotina laboratorial clínica.

\section{abstract}

Background: Copper is an essential nutrient for humans and maintenance of its adequate levels is important, since its metabolism is involved with oxidative stress and patolologies, such as Wilson's disease. In this work, a visible spectrophotometric method was validated, applied in young subjects and compared to flame atomic absorption spectrometry (FAAS) in serum copper levels determination. Methods: Serum copper concentrations were measured by FAAS and by spectrophotometry, through copper reaction with bathocuproine, $\lambda=484$ $n m$. Aqueous curves and spiked serum curves were realized to verify linearity, recovery and precision of the visible spectrophotometric method. Blood samples from 12 subjects (mean 22 years) were analyzed in both methodologies and compared to each other. The results were expressed by mean \pm standard deviation. Results: Spiked serum and aqueous curves $(\mathrm{n}=5)$ showed coefficient of regression superior to 0.99 and inter and intra-day coefficient of variation lower than $15 \%$. The serum copper values found to Vis spectrophotometric method were $1.17 \pm 0.39$ and $0.73 \pm 0.14 \mathrm{mg} / \mathrm{l}$ to women and men, respectively. To FAAS $1.13 \pm 0.43$ and $0.59 \pm 0.13 \mathrm{mg} / \mathrm{l}$ were found to women and men, respectively. Both results showed a significant Pearson correlation $(r=0.946 ; p<0.05)$. Besides, serum copper levels were significantly higher in women than in men $(\mathrm{p}<0.05)$. Conclusion: The Vis spectrophotometric method demonstrated to be linear, reproducible and applied, offering a reliable alternative to FAAS copper quantification. Moreover, Vis spectrophotometry is a simple, quickly and not expensive technique, and it could be widely used as routine in clinical laboratory. key words

Copper

Serum

FAAS

Vis spectrophotometry

1. Acadêmica do Curso de Farmácia, Departamento de Análises Clínicas e Toxicológicas, Centro de Ciências da Saúde da Universidade Federal de Santa Maria (CCS/UFSM).

2. Mestre em Ciências Farmacêuticas, Departamento de Análises Clínicas e Toxicológicas do CCS/UFSM.

3. Mestranda da Pós-Graduação em Ciências Farmacêuticas, Departamento de Análises Clínicas e Toxicológicas do CCS/UFSM.

4. Doutor em Medicina, Departamento de Clínica Médica, Centro de Ciências da Saúde da UFSM.

5. Doutora em Química, Departamento de Química, Centro de Ciências Naturais e Exatas (CCNE) da UFSM.

6. Doutor em Química, Departamento de Química do CCNE/UFSM.

7. Farmacêutica Bioquímica, Departamento de Química do CCNE/UFSM.

8. Doutora em Farmácia Bioquímica, Departamento de Análises Clínicas e Toxicológicas do CCS/UFSM. 


\section{Introdução}

O cobre é um nutriente essencial, utilizado em várias funções fisiológicas e bioquímicas, tais como, eritropoiese ${ }^{(10)}$ e resposta imune do organismo(13). Estudos têm demonstrado que o cobre é necessário para o funcionamento de um grande número de enzimas, principalmente aquelas que catalisam reações redox ${ }^{(23)}$, sendo um importante co-fator para superóxido dismutase (SOD), lisil oxidase, citocromo c oxidase e ceruloplasmina ${ }^{(19,25,28)}$.

É um metal redox fortemente ativo, encontrado em pequenas quantidades no organismo humano, tanto na forma de íon cúprico (Cu II) - predominante - como na de íon cuproso (Cu I)(1) - no interior das células ${ }^{(19)}$. Noventa por cento do Cu sérico está ligado a ceruloplasmina, e a quantificação desse metal é realizada no soro na maioria dos estudos ${ }^{(27)}$.

Trabalhos prévios mostraram que a deficiência de cobre pode provocar anemia ${ }^{(10)}$, bem como diminuição na produção de energia e anormalidades nos metabolismos da glicose (o que pode contribuir em alguns casos para o desenvolvimento de diabetes) ${ }^{(32)}$ e do colesterol (podendo causar problemas cardíacos) $)^{(15,20)}$. Além disso, provoca diminuição na atividade da enzima superóxido dismutase, que é uma enzima antioxidante ${ }^{(34)}$, pois catalisa a conversão de ânions superóxidos em peróxidos de hidrogênio. Dessa forma, a deficiência de cobre compromete vários sistemas de defesa do organismo. Em contrapartida, talvez como resposta adaptativa ao decréscimo de cobre, a glutationa reduzida, o principal antioxidante endógeno, encontra-se aumentada nesses $\operatorname{casos}^{(4,5)}$.

Assim, como a diminuição do cobre está associada ao estresse oxidativo, sua elevação também causa toxicidade relacionada com a peroxidação lipídica de membranas, uma vez que, quando encontrado na forma monovalente (Cu I), o metal está disponível para transferir um elétron. Esse processo gera, assim, espécies reativas de oxigênio (EROs), tais como radicais hidroxila, peróxido de hidrogênio e íons superóxido( ${ }^{(9)}$, que estão intimamente ligados ao estresse oxidativo, provocando dano celular, oxidação protéica e

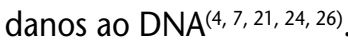

Geralmente, casos de intoxicação por cobre são decorrentes da ingestão de bebidas contaminadas pelo metal ou da alta ingestão de sais do mesmo ${ }^{(29)}$ e podem representar alto risco, principalmente para indivíduos portadores da doença de Wilson ${ }^{(3,6)}$. Essa doença é autossômica recessiva, caracterizada por deficiência na proteína transportadora de cobre: a ceruloplasmina. Dessa forma, há aumento da concentração hepática de cobre, que pode desencadear cirrose, e uma redução na sua excreção pela bile ${ }^{(18)}$, o que contribui para seu aumento na forma livre sangüínea.

Diante da importância do cobre no organismo humano, suas quantificação e monitoração são de grande valia, uma vez que as concentrações essenciais e tóxicas são muito próximas. Os métodos analíticos mais utilizados para sua quantificação são espectrometria de emissão atômica em plasma indutivamente acoplada (ICP-AES) $)^{(30,31,33)}$ e espectrometria de absorção atômica com chama (EAA-chama), além de métodos de fluorescência indiretos usando ácido tiobarbitúrico e 1-10 fenantrolina ${ }^{(8)}$. Porém, a maioria desses métodos requer equipamentos específicos e sofisticados, não disponíveis em muitos laboratórios clínicos.

Neste trabalho otimizou-se uma metodologia espectrofotométrica simples, rápida e de baixo custo para quantificação de cobre sangüíneo, que depois foi aplicada em um grupo de jovens saudáveis, uma vez que há deficiência de pesquisas nessa faixa etária. O procedimento consistiu na formação do complexo Cu-batocuproína (BCS), após desproteinização, e quantificação em $484 \mathrm{~nm}$. Os resultados obtidos foram comparados, verificando-se ainda a existência de correlação com o método EAA-chama.

\section{Materiais e métodos}

\section{Equipamentos}

Foram utilizados espectrofotômetro UV-Visível modelo 1201 Shimadzu, espectrômetro de absorção atômica com chama (Analytik Jena, mod. NovAA 315 BU com lâmpada de deutério para correção de background), centrífuga Heraeus $\mathrm{GMBH}$, vórtex Heidolph Reax top, banho Gerhardt, balança Sartorius e peagâmetro Mettler Toledo MP 220.

\section{Reagentes e soluções}

Sulfato de cobre pentaidratado (Merck), ácido tricloroacético (Vetec), ácido ascórbico de grau analítico (Vetec), ácido clorídrico (Vetec), batocuproína (2,9-dimetil-4,7difenil-1,10 fenantrolina dissulfônica ácida - BCS) (Sigma), água ultrapura obtida através de sistema Milli-Q.

Solução padrão estoque de $1 \mathrm{~g} / \mathrm{l}$ de cobre. Solução padrão intermediária de cobre $0,1 \mathrm{~g} / \mathrm{l}$. Soluções padrões para trabalho de 5, 10 e $20 \mathrm{mg} / \mathrm{l}$ de cobre. Essas soluções devem ser preparadas diariamente.

Solução tricloroacético (TCA) $10 \%(\mathrm{~m} / \mathrm{v})$, solução redutora de ácido ascórbico $10 \%(\mathrm{~m} / \mathrm{v})$, solução ácido 
clorídrico $(\mathrm{HCl}) 1 \mathrm{M}$ e reagente de cor batocuproína $5 \mathrm{mM}$, em tampão fosfato; $\mathrm{pH} 7.5$.

\section{Validação metodológica}

O procedimento para determinação do Cu por espectrofotometria visível seguiu-se da seguinte forma: para a curva com adição de padrão em matriz biológica foram adicionados $200 \mu$ l de solução fisiológica ou solução padrão de cobre a $1 \mathrm{ml}$ de soro e $500 \mu \mathrm{lde} \mathrm{HCl} 1 \mathrm{M}$, para que ocorresse a liberação do Cu das proteínas ligantes, seguida de homogeneização por um minuto em vórtex. A amostra foi, então, mantida por 10 minutos em banho a $37^{\circ} \mathrm{C}$ e agitada mais um minuto em vórtex. Depois adicionaram-se 500 $\mu \mathrm{l}$ de TCA $10 \%(\mathrm{~m} / \mathrm{v})$ para desproteinização, agitando-a por mais um minuto em vórtex. Após centrifugação de 10 minutos a $5.000 \mathrm{rpm}$, um volume de $1 \mathrm{ml}$ do sobrenadante foi homogeneizado por 30 segundos em vórtex com $500 \mu \mathrm{l}$ de ácido ascórbico 10\% (m/v) para que ocorresse redução do cobre total. Depois foram adicionados $500 \mu \mathrm{l}$ de batocuproína $5 \mathrm{mM}$, realizando-se as leituras espectrofotométricas em $484 \mathrm{~nm}$.

Para validação metodológica, os parâmetros linearidade, reprodutibilidade, precisão e exatidão foram avaliados. Assim, curvas de calibração $(n=5)$ foram feitas com adição de padrão em pool de soro, nas concentrações de $0 ; 0,5 ; 1$; 2 e 4 mg/l. O nível basal não apresenta adição de padrão, contendo apenas a quantidade normal de $\mathrm{Cu}$ no soro. A partir dessas curvas avaliou-se o coeficiente de variação (CV\%) intra e interdia e suas respectivas recuperações. Exatidão foi obtida através do erro sistemático e expressa em porcentagem do viés. Além disso, os parâmetros limite de detecção (LD) e de quantificação (LQ) foram calculados para o método espectrofotométrico(2).

Para a realização das curvas aquosas $(n=5)$ foram utilizadas soluções-padrão como sobrenadante, nas concentrações de $0 ; 0,5 ; 1 ; 1,5$ e $2 \mathrm{mg} / \mathrm{l}$.

\section{Aplicação}

O estudo foi realizado com amostras de um grupo de 12 jovens saudáveis $(n=12)$, divididos em 6 mulheres e 6 homens, com idades de 18 a 26 anos. Todos os indivíduos residiam na cidade de Santa Maria (RS), e não foram considerados dados relacionados com ocupação, nível socioeconômico e dieta por tratar-se de um grupo homogêneo.

Previamente à coleta, tubos e ponteiras utilizados no procedimento foram deixados em solução de ácido nítrico a $10 \%$ e álcool $25 \%$ (v/v) por 24 horas e depois lavados com água Milli-Q. Esse procedimento foi realizado para excluir a possibilidade de contaminação do material por cobre, que poderia levar a resultados errôneos.

As amostras foram coletadas por venopunção, e o soro foi obtido por coagulação espontânea do sangue. As amostras foram, então, centrifugadas a $5.000 \mathrm{rpm}$ por 10 minutos. $\mathrm{O}$ soro foi separado e acondicionado a $-20^{\circ} \mathrm{C}$ até análise. Amostras hemolisadas foram excluídas.

Para determinação de Cu por EAA-chama, $1 \mathrm{ml}$ de soro foi diluído em água Milli-Q para um volume final de $10 \mathrm{ml}$. As amostras foram lidas sob as condições descritas na Tabela 1.

Condições de operação do EAA-chama

Tabela 1 para determinação de cobre

\begin{tabular}{lc}
\hline Condições da chama & \\
Fluxo do gás acetileno (I/min) & 13,5 \\
Fluxo de ar (I/min) & 2 \\
Monocromador & \\
Comprimento de onda (nm) & 324,8 \\
Corrente da lâmpada (mA) & 4 \\
Fenda espectral (nm) & 0,5 \\
\hline
\end{tabular}

\section{Análise estatística}

Para avaliar a correlação entre os métodos, compararamse os resultados obtidos por espectrofotometria visível e por EAA-chama, que são diferentes técnicas analíticas. Assim, a correlação entre os métodos foi realizada pelo teste de Pearson, seguindo a distribuição normal das variáveis.

Os resultados obtidos foram expressos na forma de média \pm desvio padrão. A análise estatística foi realizada pelo programa Statistica versão 6.0, considerando-se resultados significativos com $p<0,05$.

\section{Resultados e discussão}

Depois da escolha do melhor tratamento da amostra, o método espectrofotométrico para determinação de cobre sérico foi validado segundo normas da Agência Nacional de Vigilância Sanitária (Anvisa) ${ }^{(2)}$. As curvas com adição de padrão $(n=5)$ e as em solução aquosa $(n=5)$ apresentaram, respectivamente, as seguintes equações: $y=0,0616 x$ $+0,0208$ e $y=0,1084 x+0,0059$, sendo os coeficientes 
de regressão (r2) 0,996 e 0,999, respectivamente. Isso demonstra a linearidade e a reprodutibilidade do método espectrofotométrico.

A precisão do método, ou seja, a proximidade dos resultados obtidos em uma série de medidas foi avaliada pelas variações intra e interdia, expressas em percentagem pelo coeficiente de variação (CV\%). As diferentes concentrações das curvas com adição de padrão apresentaram entre si um $\mathrm{CV}<15 \%$ para todos os pontos. As recuperações obtidas a partir das adições de padrão também mostraram valores muito próximos da totalidade, superiores a $85 \%$, sendo o método considerado satisfatoriamente aplicável, como pode ser visto na Tabela 2.

LD e LQ foram determinados avaliando-se o sinal do ruído através de leituras do branco aquoso, 1:3 e 1:10, respectivamente. Para LD o resultado obtido foi de 0,069 $\mathrm{mg} / \mathrm{l}$ e para $\mathrm{LQ}$, de $0,229 \mathrm{mg} / \mathrm{l}$. No método de EAA-chama, o LD encontrado na literatura é de $0,010 \mathrm{mg} / \mathrm{l}$ e o LQ, de $0,035 \mathrm{mg} / /^{(17)}$.

A exatidão do método espectrofotométrico foi avaliada através do erro sistemático, ou tendenciosidade, e expressa em porcentagem do viés. Os resultados encontrados para as concentrações $0,5 \mathrm{mg} / \mathrm{l} ; 1 \mathrm{mg} / \mathrm{l} ; 2 \mathrm{mg} / \mathrm{l}$ e $4 \mathrm{mg} / \mathrm{l} \mathrm{da}$ curva com adição de matriz foram, respectivamente -10\%; $-11,3 \% ;-10 \%$ e $-10 \%$. Amostras biológicas até $15 \%$ são consideradas aceitáveis pela Anvisa ${ }^{(2)}$.

A aplicação do método espectrofotométrico para quantificação do cobre sérico está apresentada na Tabela 3. De acordo com a literatura, as concentrações de cobre sérico variam de acordo com o sexo; os valores de referência para mulheres adultas encontram-se entre 0,8 e 1,5 mg/l e para homens adultos entre 0,7 e 1,4 mg//(12).

Comparando-se a técnica espectrofotométrica com o método EAA-chama, obteve-se o coeficiente de correlação de Pearson significativo $(r=0,946 ; p<0,05)$, conforme a Figura 1, feito pelo programa de estatística Statistica versão 6.0. Dessa forma, uma boa correlação entre os métodos foi obtida.

Pôde-se observar que os resultados pelos dois métodos de análise foram comparáveis, e os níveis de cobre sérico encontrados para mulheres foram significativamente maiores do que os encontrados para os homens $(p<0,05)$, confirmando o que já havia sido descrito anteriormente ${ }^{(11)}$.

Alguns estudos têm demonstrado que essas diferentes concentrações são provavelmente decorrentes da dieta diferenciada entre homens e mulheres, bem como do diferente modo de absorção dos alimentos por ambos os $\operatorname{sexos}^{(14)}$.

Valores abaixo ou acima dos considerados referência podem resultar em patologias. Exemplos dessas patologias são encontrados em estudos anteriores que relataram casos de pacientes portadores da doença de Wilson, com níveis séricos de cobre de $0,67 \mathrm{mg} / /^{(16)}$, e pacientes com hepatite viral crônica, com valores de cobre sanguíneo superiores a $1,60 \mathrm{mg} / \mathrm{I}^{(22)}$.

O método espectrofotométrico desenvolvido e validado neste trabalho pode ser seguramente utilizado na quantificação dos níveis séricos de cobre das patologias citadas acima e em outras, uma vez que obteve boa correlação com o método EAA-chama, utilizado na quantificação de metais traços como o cobre. Apesar de ser robusto, de fácil utiliza-

\section{Tabela 2}

Tabela 2 método espectrofotométrico obtido a partir das curvas com adição de padrão $(n=5)$

\begin{tabular}{lccc}
\hline Concentração & CV\% intradia & CV\% interdia & Recuperação (\%) \\
$0,5 \mathrm{mg} / \mathrm{l}$ & 1,5 & 3,9 & 89,2 \\
$1 \mathrm{mg} / \mathrm{l}$ & 6,7 & 4,6 & 88,1 \\
$2 \mathrm{mg} / \mathrm{l}$ & 0,6 & 5,8 & 89,8 \\
$4 \mathrm{mg} / \mathrm{l}$ & 3,6 & 5,5 & 89,7 \\
\hline
\end{tabular}

\section{Tabela 3 Comparação do método espectrofotométrico com o método EAA-chama}

\begin{tabular}{lcc}
\hline & Espectrofometria $(\mathrm{mg} / \mathrm{l})$ & EAA chama $(\mathrm{mg} / \mathrm{l})$ \\
Homens $(n=6)$ & $0,72 \pm 0,14^{*}$ & $0,61 \pm 0,13^{*}$ \\
Mulheres $(n=6)$ & $1,17 \pm 0,39^{*}$ & $1,13 \pm 0,43^{*}$ \\
\hline
\end{tabular}

*Resultados são expressos em média \pm desvio-padrão; $p<0,05$. 


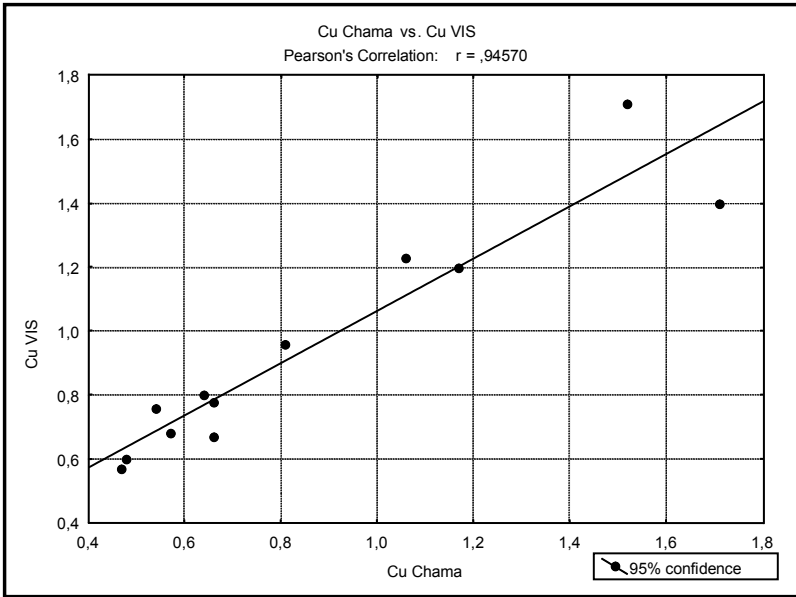

Figura 1 - Correlação entre os métodos espectrofotometria e EAA-chama

ção e rápido, o método EAA-chama apresenta desvantagens por utilizar gás tóxico (acetileno) durante a detecção do metal, assim como por ser uma técnica de alto custo que utiliza equipamentos específicos e sofisticados.

Por isso, a padronização da técnica de espectrofotometria Vis neste trabalho fornece uma alternativa confiável para a determinação do Cu na medicina laboratorial de rotina, uma vez que é de fácil manipulação, rápida e de baixo custo.

\section{Conclusão}

O método espectrofotométrico proposto mostrou-se linear, preciso, exato e reprodutível. Além disso, demonstrou correlação positiva significativa com o método comparativo EAA-chama.

Através da aplicação desse método em amostras reais, foi possível verificar que os níveis séricos de cobre dos jovens avaliados mostraram-se comparáveis com dados da literatura. Dessa forma, torna-se possível sugerir sua aplicabilidade em análises laboratoriais de rotina por ser um método fácil, rápido, de simples procedimento e fornecer resultados seguros e precisos.

\section{Agradecimentos}

Ao suporte financeiro concedido pelo Serviço Alemão de Intercâmbio Acadêmico (DAAD) (Sachmittelprogramm für Hochschulen Entwickeltländern 2005). Solange Cristina Garcia possui Bolsa de Pesquisadora concedida pelo ConseIho Nacional de Desenvolvimento Científico e Tecnológico (CNPq). Angela Maria Moro recebe Bolsa de Iniciação Científica do CNPq.

\section{Referências}

1. BARCELOUX, D.G. Copper review. Clin Toxicol, v. 37, n. 2, p. 217-30, 1999.

2. BRASIL - Agência Nacional de Vigilância Sanitária (ANVISA), Brasil. Resolução n 899, de 29 de maio de 2003. Diário Oficial da República Federativa do Brasil. Brasília, 2 de junho de 2003. Disponível em: http://www.anvisa.gov. br/legis/resol/2003/re/899_03re.htm.

3. BREWER, G.J. Is heterozygosity for a Wilson's disease gene defect and important underlying of infantile and childhood copper toxicosis syndromes? (editorial). J Trace Elem Exp Med, v. 13, p. 249-54, 2000.

4. CHAO, P.Y.; ALLEN, K.G. Glutathione production in copperdeficient isolated rat hepatocytes. Free Radic Biol Med, v. 12, p. 145-50, 1992.

5. CHEN, Y.; SAARI, J.T.; KANG, Y.J. Weak antioxidant defenses make the heart target for damage in copperdeficient rats. Free Radic Biol Med, v. 17, p. 529-36, 1994.

6. EIFE, R. et al. Chronic poisoning by copper in top water: I. Copper intoxication with predominantly gastrointestial symptoms. Eur J Med Res, v. 4, p. 219-23, 1999.

7. FIELDS, M.; LEWIS, C.G. Hepatic iron overload may contribute to hypertriglyceridemia and hypercholesterolemia in copper-deficient rats. Metabolism, v. 46, p. 377-81, 1997.

8. GUTTERIDGE, J.M.C. Copper-phenanthroline-induced site- specific oxygen-radical damage to DNA: detection of loosely bound trace copper in biology fluids. Biochem J, v. 218, p. 983-85, 1984.

9. HALLIWELL, B.; GUTTERIDGE, J.M. Oxygen toxicity, oxygen radicals, transition metals and disease. Biochem J, v. 219, p.1-14, 1984.

10. HART, E.B. et al. Copper is supplement to iron for hemoglobin building in rat. J Biol Chem, v. 77, p. 797812, 1928.

11. HELGELAND, K.; HAIDER, T.; JONSEN, J. Copper and zinc in humans in Norway. Relationship to geography, sex and age. Scand J Clin Lab Invest, v. 42, n. 1, p. 35-9, 1982.

12. HENRY, B.J. Diagnósticos clínicos e tratamento por métodos laboratoriais. 19 ed. São Paulo: Manole, 1999. p. 191

13. HUANG, Z.L.; FAILA, M.L. Copper deficiency suppresses effector activities of differentiated U937 cells. J Nutr, v. 130, p. 1536-42, 2000.

14. JOHNSON, P.E.; MILNE, D.B.; LYKKEN, G.I. Effects of age and sex on copper absorption, biological half-life, and status in humans. Am J Clin Nutr, v. 56, n. 5, p. 917-25, 1992.

15. KLEVAY, L.M. Dietary copper and risk of coronary heart disease. Am J Clin Nutr, v. 71, n. 5, p. 1213-14, 2000. 
16. KOMATSU, H. et al. Hepatic copper concentration in children underground living related liver transplantation due to Wilsonian fulminant hepatic failure. Clin Transplant, v. 16, n. 3, p. 227-32, 2002.

17. KORN, M.G.A. et al. Determinação de Mn, Cu e Zn em matrizes salinas após separação e pré-concentração usando Amberlite XAD-7 impregnada com vermelho de Alizarina S. Quím Nova, v. 25, n. 6b, p. 1086-90, 2002.

18. LI, Y. et al. Spontaneous hepatic copper accumulation in Long-Evans Cinnamon rats with hereditary hepatitis: a model of Wilson's disease. J Clin Invest, v. 87, p. 1858-61, 1991.

19. LINDER, M.C. et al. Copper biochemistry and molecular biology. Am J Clin Nutr, v. 63, p. 797-811, 1996.

20. LUKASKI, H.C. et al. Effects of dietary copper on human autonomic cardiovascular function. Eur J Appl Physiol Occup Physiol, v. 58, n. 1-2, p. 74-80, 1988.

21. LYNCH, S.M.; FREI, B.; MORROW, J.D. et al. Vascular superoxide dismutase deficiency impairs endothelial vasodilator function through direct inactivation of nitric oxide and increased lipid peroxidation. Arterioscler Thromb Vasc Biol, v. 17, p. 2975-81, 1997.

22. MERAM, I. et al. Plasma copper and zinc levels in chronic viral hepatitis. Saudi Med J, v. 25, n. 8, p. 1066-69, 2004.

23. MIRANDA, S. et al. The role of oxidative stress in the toxicity induced by amyloid beta-peptide in Alzheimer. Prog Neurobiol, v. 62, p. 633-48, 2000.

24. NELSON, S.K.; HUANG, C.J.; MATHIAS, M.M. et al. Copper-marginal and copper-deficient diets decrease aortic prostacyclin production and copper-dependent superoxide dismutase activity, and increase aortic lipidic peroxidation in rats. J Nutr, v. 122, p. 2101-8, 1992.

25. RUCKER, R.B. et al. Copper lisyl oxidase and extracellular matrix protein cross-linking. Am J Clin Nutr, v. 67, p. 996-1002, 1998.
26. SAARI, J.T. Copper deficiency and cardiovascular disease: role of peroxidation, glycation and nitration. Can $J$ Physiol Pharmacol, v. 78, p. 848-55, 2000.

27. SONGCHITSOMBOOM, S.; KOMINDR, S. Serum zinc and copper in healthy adults living in Bangkonk and surrounding districts. J Med Assoc, v. 79, p. 550-7, 1996.

28. TAINER, J.A. et al. Structure and mechanism of copper zinc superoxide dismutase. Nature, v. 306, p. 284-7, 1983.

29. URIU-ADAMS, J.Y.; KEEN, C.L. Copper, oxidative stress, and human health. Mol Aspects Med, v. 26, n. 4-5, p. 268-98, 2005.

30. VANHOE, $\mathrm{H}$. et al. Determination of iron, cobalt, cooper, zinc, rubidium, molybdenum and cesium in human serum by inductively coupled plasma mass spectrometry. Anal Chem, v. 61, p. 1851-7, 1989.

31. VAUGHAN, M.; BAINES, A.; TEMPLETON, D.M. Multielement analysis of biology samples by inductively coupled mass spectrometry. II. Rapid survey method for profiling trace elements in body fluids. Clin Chem, v. 37, n. 2, p. 210-5, 1991.

32. WASHINGTON, D.C. Copper dietary reference intakes: vitamin $\mathrm{A}$, vitamin $\mathrm{K}$, arsenic, boron, chromium, copper, iodine, iron, manganese, molybdenum, nickel, silicon, vanadium, and zinc. Food and Nutrition Board, p. 224-57, 2002.

33. XIA, J. et al. A novel voltametric method for the direct determination of copper in complex environmental samples. Anal Sci, v. 20, n. 7, p. 1037-41, 2004.

34. YADRICK, M.K.; KENNEY, M.A.; WINTERFELDT, E.A. Iron, copper and zinc status: response to supplementation with zinc and iron adult female. Am J Clin Nutr, v. 49, p. 145-50, 1989. 